\title{
A Case of Exfoliation of Oral Mucosal Epithelium in a Patient with Anti-Desmoglein 1 Antibody-Positive and Anti-Desmoglein 3 Equivocal Antibody
}

\author{
Michiko Ozawa, Yoshinori Jinbu, Hiromi Hayashi, Tadahide Noguchi, Yoshiyuki Mori \\ Department of Dentistry, Oral and Maxillofacial Surgery, Jichi Medical University, Tochigi, Japan \\ Email: oralsurg@jichi.ac.jp
}

How to cite this paper: Ozawa, M., Jinbu, Y., Hayashi, H., Noguchi, T. and Mori, Y. (2017) A Case of Exfoliation of Oral $\mathrm{Mu}-$ cosal Epithelium in a Patient with AntiDesmoglein 1 Antibody-Positive and Anti-Desmoglein 3 Equivocal Antibody. Open Journal of Stomatology, 7, 299-304. https://doi.org/10.4236/ojst.2017.76024

Received: September 24, 2014

Accepted: June 26, 2017

Published: June 29, 2017

Copyright $\odot 2017$ by authors and Scientific Research Publishing Inc. This work is licensed under the Creative Commons Attribution International License (CC BY 4.0).

http://creativecommons.org/licenses/by/4.0/

cC) (7) Open Access

\begin{abstract}
Pemphigus is an autoimmune bullous disease observed with lesions in the skin and mucosa. Pemphigus is classified by antibodies against desmogleins, which is cadherin type intercellular adhesion factors involved in adhesion between epidermal cells. In this case, because erosion of the oral mucosa was the primary symptom, a relationship with membrane-dominant pemphigus vulgaris was strongly suspected. And in terms of histopathology, findings not conflicted with pemphigus vulgaris were observed, but given all these different findings, the results did not correspond with bullous pemphigoid in clinical findings, and with pemphigus foliaceus and pemphigus vulgaris in various testing results, leading us to believe this represented a very rare case. We started oral health care, and when application of steroid ointment to the entire surface of the mucosa was continued, symptoms disappeared within approximately 2 months. In this case, relapse has not yet occurred and periodic follow-up was continued.
\end{abstract}

\section{Keywords}

Anti-Desmoglein 3 Antibodies, Anti-Desmoglein 1 Antibodies, Autoimmune Bullous Disease, Oral Mucosa

\section{Introduction}

Autoimmune bullous diseases' occurring in the oral mucosa and exhibiting antiepidermal cell membrane antibodies is a pemphigus vulgaris involving anti-desmoglein 3 antibodies. In contrast, pemphigus foliaceus is a disease in which anti-desmoglein 1 antibodies are principally involved. The main presentation of 
pemphigus foliaceus is skin lesions and generally no involvement of the oral mucosa.

We report herein our experience about treating a rare case exhibiting anti-desmoglein 1 antibody-positive and anti-desmoglein 1 equivocal antibody results and peeling of the oral mucosa over a wide area.

\section{Case Report}

The patient was a 67-year-old man who was referred to the Department of Dentistry at Nasu Red Cross Hospital in October 2010 with chief complaints of sharp pain and epithelial peeling of the oral cavity. He had a history of progressive aphasia, hypertension, and gallstones and had been admitted to the Department of Internal Medicine of the same hospital in September 2010 for gallstone treatment. He started to complain of sharp pain inside the mouth during that previous hospitalization, showing no improvement despite administration of amphotericin B under suspicion of oral candidiasis. At this stage, he was referred to this department.

Systematic examination revealed no noteworthy findings, with no abnormalities of the skin. He does not take drugs; there was no relationship to the lesion. The clinical diagnosis was pemphigus (Figure 1).

Biopsy was conducted during the initial consultation under the clinical diagnosis mentioned above. Epithelial peeling was observed from directly above the basal layer to the stratum spinosum (Figure 2), leading to a diagnosis not histopathologically conflicting with pemphigus vulgaris. Under direct immunofluorescence, mild deposition of immunoglobulin IgG and complement $\mathrm{Clq}$ was observed along the basal membrane. However, deposition of IgG corresponding to the epithelial cell membrane was not observed (Figure 3). Indirect immunofluorescence yielded negative results. Upon blood testing during the initial consultation, enzyme-linked immunosorbent assay (ELISA) yielded positive results
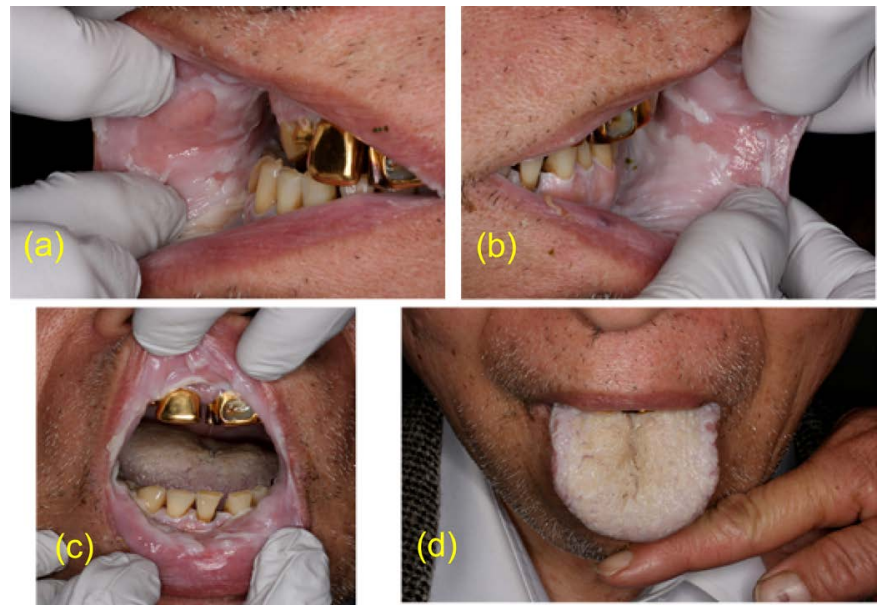

Figure 1. Intraoral view: The entire oral mucosa was edematous and whites ((a)-(c)). And the epithelial surface layer was peeled. However, bleeding and redness were not observed. A notable white coating was observed on the tongue (d), and both Candida albicans and Candida krusei were detected. 


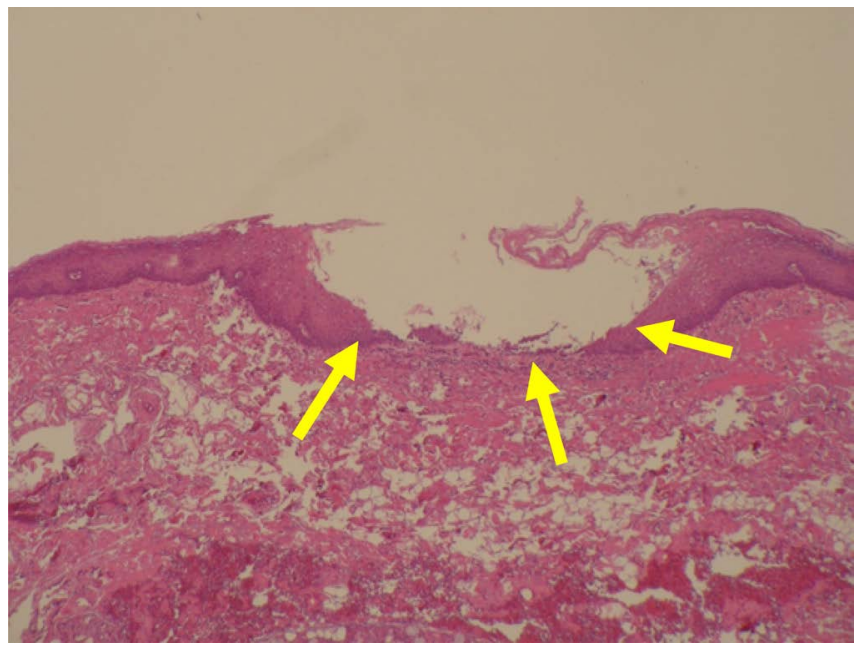

Figure 2. Histopathological features: Epithelial peeling was observed from directly above the basal layer to the spinous cell layer (hematoxylin and eosion stain, $\times 200$ ).

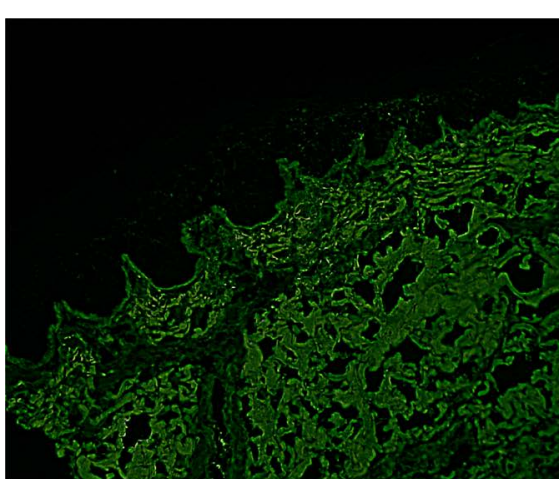

(a)

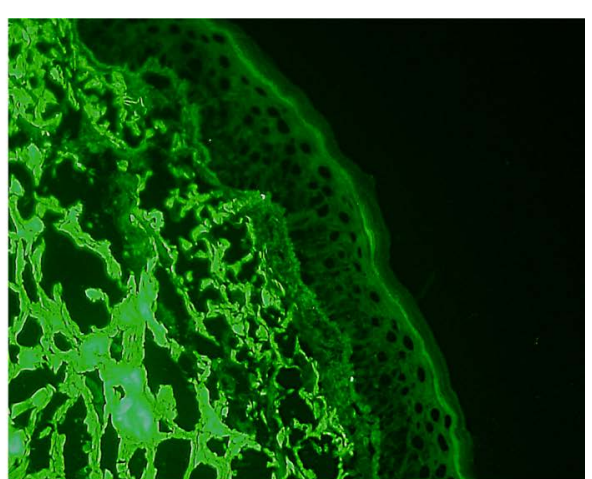

(b)

Figure 3. Direct immune-fluorescence features: Mild deposition of IgG (a) and complement C1q (b) was observed along the basal membrane; however, deposition of IgG corresponding to the epithelial cell membrane was not observed (direct immuno-fluorescence microscopy $\times 200$ ).

for anti-desmoglein 1 antibodies and equivocal results for anti-desmoglein 3 antibodies (Table 1). Pemphigus was suspected from biopsy and blood test results, so a consultation was conducted in the Departments of Oral Surgery and Dermatology at Jichi Medical University Hospital 5 days following the initial consultation. Careful examination ruled out the presence of skin manifestations and malignant tumors. Triamcinolone acetonide was prescribed from 13 days by the Department of Dermatology, and oral health care was commenced. Food debris and plaque were removed, the oral mucosa was scraped with a pledget, and the peeled epithelium was removed. When steroid ointment application to the entire surface of the mucosa was continued, symptoms disappeared within approximately 2 months (Figure 4). No marked differences were observed in values of anti-desmoglein antibodies 1 and 3 within the 5 months from October 2010 to February 2011 (Figure 5). Moreover, no relapse of symptoms has been observed until now. The patient has given their consent for the Case reports to be published. 
Table 1. Laboratory data on admission.

\begin{tabular}{cccc}
\hline $\mathrm{WBC}^{*}$ & $6800 / \mathrm{mm}^{3}$ & $\mathrm{Alb}$ & $3.7 \mathrm{~g} / \mathrm{dl}$ \\
$\mathrm{RBC}^{*}$ & $395 \times 104 / \mathrm{mm}^{3}$ & $\mathrm{UN}^{*}$ & $12.7 \mathrm{mg} / \mathrm{dl}$ \\
$\mathrm{Ht}$ & $37.6 \%$ & $\mathrm{CRE}^{*}$ & $0.78 \mathrm{mg} / \mathrm{dl}$ \\
$\mathrm{Hb}$ & $12.5 \mathrm{~g} / \mathrm{dl}$ & $\mathrm{CRP}^{*}$ & $0.31 \mathrm{mg} / \mathrm{dl}$ \\
$\mathrm{Plt}$ & $24.3 \times 104 / \mathrm{mm}^{3}$ & anti-BP180 antibodies & 8 \\
$\mathrm{GOT}^{*}$ & $17 \mathrm{IU} / \mathrm{l}$ & anti-desmoglein 1 antibodies & 51 \\
$\mathrm{GPT}^{*}$ & $19 \mathrm{IU} / \mathrm{l}$ & anti-desmoglein 3 antibodies & 8 \\
$\mathrm{TP}^{*}$ & $7.3 \mathrm{~g} / \mathrm{dl}$ & & \\
\hline
\end{tabular}

WBC ${ }^{*}$ : white blood cell $\mathrm{RBC}^{*}$; red blood cell GOT*: glutamic oxaloacetic transaminase; GPT*: glutamic pyruvic transaminase $\mathrm{TP}^{*}$ : total protein $\mathrm{UN}^{*}$ : Urea nitrogen; $\mathrm{CRE}^{*}$ : creatinine $\mathrm{CRP}^{*}$ : C-reactive protein; Results for anti-desmoglein 1 antibodies were positive and those for anti-desmoglein 3 antibodies were equivocal.

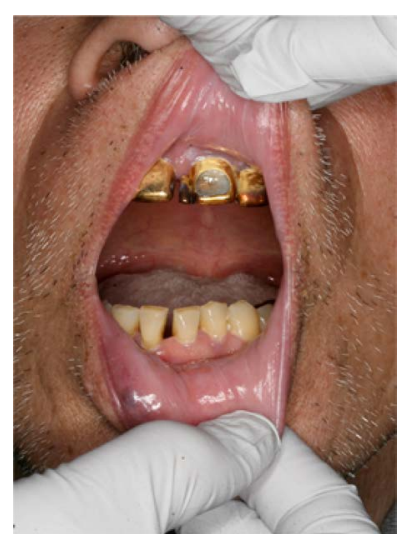

Figure 4. Intraoral view: epithelial peeling of the oral mucosa disappeared over a 2-month period.



Figure 5. Changes in the antibody titer: no large difference was observed in values over a 5-month period. 


\section{Discussion}

Pemphigus is an autoimmune bullous disease observed with lesions in the skin and mucosa. Intraepidermal blistering due to acantholysis occurs as a result of adhesion among histopathologically impaired epidermal cells. In this disease, autoantibodies to the epidermal cell membrane surface are immunopathologically deposited or observed in circulating blood. The antigen proteins involved in pemphigus are desmogleins, which is cadherin type intercellular adhesion factors involved in adhesion among epidermal cells.

The male-to-female ratio of pemphigus is reportedly $1: 1.5$, showing a slight predilection toward women in bullous diseases. In terms of age distribution, patients in their sixties are the most common, with the age of onset is also the most common among patients in their sixties. Regarding the disease type, pemphigus vulgaris is the most common, at $65 \%$, followed by pemphigus foliaceus at $23 \%$. Among these, pemphigus vulgaris is the representative autoimmune bullous disease affecting oral mucosa.

Pemphigus vulgaris is then classified into two types. One type is mucosa advantage type observed with symptoms only in the oral mucosa with anti-desmoglein 3 antibody as the antigen. Other type is mucocutaneous type observed with blistering is seen in the skin with anti-desmoglein 1 antibodies and anti-desmoglein 3 antibodies as the antigen. Moreover, pemphigus foliaceus is observed with only skin manifestations and antibodies against desmoglein 1 .

In this case, because erosion of the oral mucosa was the primary symptom, a relationship with membrane-dominant pemphigus vulgaris was strongly suspected. Moreover, in terms of histopathology, peeling of the epithelium was observed from directly above the basal layer to the stratum spinosum, and findings not conflicted with vulgaris pemphigus were observed.

Meanwhile, direct immunofluorescence analysis showed a small amount of IgG deposition corresponding to the basal membrane. Generally, IgG deposition is not a finding in pemphigus because it is observed among the epidermal cells, and a relationship with bullous pemphigoid, in which IgG corresponds to the basal membrane, was suspected.

Anti-desmoglein 1 antibodies were positive among serum antibodies according to ELISA. Pemphigus foliaceus is an autoimmune bullous disease with positive results for anti-desmoglein 1 antibodies. Generally, the main symptoms of pemphigus foliaceus are redness accompanying scaling occurring on the skin along with flaccid blisters, and erosion. However, in the present case, skin manifestations were not observed and lesions were only apparent in the oral mucosa. Such findings suggested a different diagnosis from the results of serum antibody testing and clinical findings.

Given all these different finding, the results did not correspond with bullous pemphigoid in clinical finding, and with pemphigus foliaceus and pemphigus vulgaris in various testing results, leading us to believe this represented a very rare case. To the best of our knowledge, no reports of similar results have been published previously [1] [2] [3] [4] [5]. 
In this case, relapse has not yet occurred, and oral care is still being conducted, along with follow-up. Generally, with pemphigus, steroid therapy to suppress antibody generation becomes the main constituent of treatment, and local drug treatment is conducted to prevent infection, protect the ulcer surface, and promote epithelization. In the present case, triamcinolone acetonide application was continued along with oral care and ointment application, with symptoms recovering over the course of 2 months following the initial consultation. Periodic follow-up was continued because the symptoms may relapse in the future, and steroid intake and therapy or local drugs must be selected based on the symptoms and severity. Regarding pemphigus, a change in the clinical condition may be perceived by periodically measuring antibody levels [5]. One report has mentioned that measuring antibody levels periodically is also effective for evaluating disease progression [6]. In such cases, serum antibody levels were measured for 5 months following the initial consultation. However, no significant changes were observed in the value thereof. Periodically measuring serum antibody levels and conducting a careful follow-up of the course will be necessary in the future.

\section{References}

[1] Wada, I., Shibasaki, O. and Nakajima, M. (2010) A Case of Mucosal Dominant Pemphigus Vulgaris. Japan Society of Stomato-Pharyngology, 2, 227-230.

[2] Sakai, S., Nitta, Y., Yamada, T. and Iketani, T. (1992) A Case Report of Pemphigus Foliaceus That Proceeded to Pemphigus Vulgaris. Japanese Journal of Clinical Dermatology, 1, 43-46.

[3] Kawaida, M., Katoh, H., Takaoka, T., Tanaka, M. and Sugiura, M. (1987) Four Cases of Bullous Dermatoses with Oral Mucosal Lesion. Otorhinolaryngology, 5, 595-602.

[4] Hayashi, S., Hatamochi, A., Nakano, A., Ishikawa, S., Hamazaki, Y., et al. (2010) A Case of Supposed Drug-Induced Pemphigus. The Nishinihon Journal of Dermatology, 3, 204-208. https://doi.org/10.2336/nishinihonhifu.72.204

[5] Tanaka, M., Higashiyama, M., Sakurane, J., et al. (2000) Topical Steroid Therapy for the Treatment of oral Ulcerations in Pemphigus and Pemphigoid Cases. The Japanese Journal of Dermatology, 9, 1403-1410.

[6] Asao, K., Maruo, K., Yoshino, y., et al. (2008) A Case of Pemphigus Vulgaris that Transitioned from Pemphigus Foliaceus. The Nishinihon Journal of Dermatology, 1, 21-29. https://doi.org/10.2336/nishinihonhifu.70.27 
Submit or recommend next manuscript to SCIRP and we will provide best service for you:

Accepting pre-submission inquiries through Email, Facebook, LinkedIn, Twitter, etc. A wide selection of journals (inclusive of 9 subjects, more than 200 journals)

Providing 24-hour high-quality service

User-friendly online submission system

Fair and swift peer-review system

Efficient typesetting and proofreading procedure

Display of the result of downloads and visits, as well as the number of cited articles Maximum dissemination of your research work

Submit your manuscript at: http://papersubmission.scirp.org/

Or contact ojst@scirp.org 